Fall 2009

\title{
Changing perceptions in the justification of the use of the " $N$ " word through community service work experiences: Offensive comments or terms of endearment?
}

\author{
August John Hoffman \\ Metropolitan State University \\ Julie Wallach \\ Metropolitan State University \\ Mark Graham \\ Metropolitan State University \\ Eduardo Sanchez \\ Metropolitan State University
}

Follow this and additional works at: https://digitalscholarship.unlv.edu/jpme

\section{Repository Citation}

Hoffman, August John; Wallach, Julie; Graham, Mark; and Sanchez, Eduardo (2009) "Changing perceptions in the justification of the use of the " $\mathrm{N}$ " word through community service work experiences: Offensive comments or terms of endearment?," Journal of Praxis in Multicultural Education: Vol. 4: No. 1, Article 3.

DOI: $10.9741 / 2161-2978.1002$

Available at: https://digitalscholarship.unlv.edu/jpme/vol4/iss1/3

This Article is protected by copyright and/or related rights. It has been brought to you by Digital Scholarship@UNLV with permission from the rights-holder(s). You are free to use this Article in any way that is permitted by the copyright and related rights legislation that applies to your use. For other uses you need to obtain permission from the rights-holder(s) directly, unless additional rights are indicated by a Creative Commons license in the record and/ or on the work itself.

This Article has been accepted for inclusion in Journal of Praxis in Multicultural Education by an authorized administrator of Digital Scholarship@UNLV. For more information, please contact digitalscholarship@unlv.edu. 


\section{Changing perceptions in the justification of the use of the " $\mathrm{N}$ " word through community service work experiences: Offensive comments or terms of endearment?}

\section{Cover Page Footnote}

The authors would like to thank the Center for Innovative and Engaged Learning Opportunities (CIELOS) of California State University Northridge for their generosity in providing grant money making this research possible. 


\title{
Changing Perceptions in the Justification of the Use of the " $N$ " Word through Community Service Work Experiences: Offensive Comments or Terms of Endearment?
}

\begin{abstract}
August John Hoffman, Julie Wallach, Mark Graham, and Eduardo Sanchez
The current study explored how students $(\mathrm{N}=181)$ enrolled in different levels of higher education perceive the appropriateness in the use of the " $\mathrm{N}$ " word today. We hypothesized that ethnic minority students who were actively involved in a community service project designed to improve a community college would be more likely to reject the use of the "N" word than those students who were not involved in a community service project. Results indicate significant differences exist among educational levels and the perception of the justification of the use of the "N" word, $t(83)=4.49, p<.0001$. Participants enrolled in higher education (graduate level) and community service activities were more likely to reject the use of the " $\mathrm{N}$ " word.
\end{abstract}

The issues of race, interethnic behaviors, and ethnic conflict are rapidly becoming important topics of psychosocial research today (Brody, 2007; Matsumoto \& Seung Hee Yoo, 2007). As our multiethnic society becomes increasingly characterized and defined by race, color, and economic class, so has the need to develop effective interactive skills and communication strategies that facilitate mutual understanding of how each group functions and processes languages (Ferber, 2007). Current research suggests that greater exposure to and interaction with members of different ethnic groups can improve the likelihood of positive relationships with members from culturally diverse backgrounds (Levin, van Laar, \& Sidanious, 2003). August John Hoffman is a professor of Psychology at Metropolitan State University. His research interests include community service work and
student mentoring as effective methods to reduce ethnic conflict and improve self-efficacy among community college students. Julie Wallach has
co-authored dozens of research articles with Dr. Hoffman addressing the unique relationship among community service engagement activities
with cooperative and interethnic behaviors. Ms. Wallach intends to complete her doctorate in the near future and continues publishing in the field
of psychology. (The authors would like to thank the Center for Innovative and Engaged Learning Opportunities (CIELOS) of California State
University Northridge for their generosity in providing grant money making this research possible.)

Lack of exposure and interaction with members from different ethnic and cultural groups further increases the likelihood of miscommunication through what Vorauer and Sakamoto (2006) refer to as "amplification bias" the tendency of an individual to incorrectly attribute stronger positive friendships with others than actually exist. Thus, what we are communicating to others as well as how the information is actually communicated or transmitted can play a pivotal role in establishing positive relationships with members from different ethnic groups (Hoffman \& Wallach, 2006; Lakoff, 2000). Recent research also suggests that, in some instances, in ethnic minority groups that become increasingly polarized (i.e., reductions in activities that promote assimilation and integration), language and "ethnic jargon" become increasingly more evident within social environments (Motley \& Craig-Henderson, 2007).

Perhaps more importantly, recent research suggests that the context of language and how languages are used can enhance, improve, or seriously deteriorate relationships among interethnic groups (Saucier, Hockett, \& Wallenberg, 2008). Language used in smaller ethnic minority groups (i.e., enclaves) may influence how members relate and communicate with and among each other (Bond, 1983; Brewer \& Kramer, 1984). Traditionally used racial insults, slurs, and derogatory terms used against other ethnic groups have also been noted as most frequently occurring items identified in police complaints (Stokoe, 2007).

It is interesting to note that certain key words that have been commonly used to describe friendships have also achieved a taboo status and are highly volatile when used among interethnic groups. Prejudice and ethnic slurs have been historically used against various ethnic groups as a means of maintaining barriers to assimilation to the dominant group (Bobo, 2000), and in many cases, slurs may be used as a means to elevate one's self-esteem by degrading others (Branscombe \& Wann, 1994). For example, the term "Dago" was commonly used to describe Italians during the Depression through the 1950's era, whereas "Wetback" was used during the 1940's era (and still occasionally used today) in describing Mexicans gaining illegal entry to the United States typically via the Colorado River. The term "Kraut" or "Gerry" was commonly used referring to German soldiers during World War II, and "Limey's" was also used during this time period referring to English soldiers. The derogatory term "Towel heads" has been used to describe persons of Middle Eastern descent and was used more frequently during economic crises within the United States (i.e., The Arab oil embargo of 1973-1974). Several of these racial slurs have been used more frequently during some type of conflict (i.e., war) or economic crisis, but now seem to have subsided in use due to different eras. 
Journal of Praxis in Multicultural Education, Vol. 4, No. 1 [2010], Art. 3

Perhaps one of the most historically volatile and highly controversial of all terms used today is that of the "N" word ("Nigger") - volatile in the sense that there is controversy over what the word actually means today, how it is used, and who is actually permitted to use it in public. The use of the term "N" word is yet also highly complex; it is often used among certain demographic groups as a term of affection, trust, and endearment, yet within other groups it is still considered to be vulgar in any form (Low, 2007). The term was frequently used in the southern states, but its use continues today, albeit in significantly different context.

While many of these ethnic slurs gained temporary popularity and their use gradually subsided, the "N" word has surprisingly remained as common jargon among specific cohorts or groups (typically African American) within our society. An interesting phenomenon has developed, however, where the actual pejorative nature of the term itself has now changed somewhat within some cultures or enclaves and is considered by many to have been "neutralized" or even assimilated into common everyday usage (Blair, 2001).

The topics of race and stereotypes are rapidly becoming important topics of research among ethnically diverse communities. Economic factors, direct competition for resources, and controversial political decisions (i.e., border control or immigration topics) have been correlated with increases in crimes targeted towards minority groups. The realistic conflict theory is rapidly emerging as a common reason why different ethnic groups with common needs often engage in conflict and aggression against each other (Bobo, 1983). Furthermore, the use of slurs typically associated with various ethnic groups is frequently a precursor to violence against those groups. The realistic conflict theory argues that as resources (such as food, potable water, and crude oil) become increasingly scarce, the tendency to act out aggressively against those who consume similar resources also increases. Thus, different ethnic groups often engage in conflict due to a mutual need for important and life-sustaining resources. As these needs for resources increase, conflicts often develop and racial derogatory slurs are commonly attributed to the “out-group” members (White, 1977).

Despite increasing awareness of the existence of problems that are associated with ethnic stereotypes and slurs, they continue to influence group behaviors (Correll, Park, Judd, \& Wittenbrink, 2002). Recent research has shown that attitudes among dominant and minority groups can easily influence prejudice and conflict among outgroup members and members of minority groups (DeSteno, Dasgupta, Bartlett, \& Cajdric, 2004). The use of certain derogatory terms in an attempt to demean specific ethnic groups has also become an increasingly important topic of scientific research, as members of various ethnic groups now show striking differences of opinions between what exactly constitutes a racial slur as opposed to a friendly exchange among friends. One important goal of the current study is in understanding how each ethnic group feels about the use of the "N" word and if it can (or should) be used in a mainstream or "legitimate" (i.e., colloquial) manner.

\section{The Origin of the "N" Word}

A review of the history of the use of the "N" word identifies the origin of the word dating back to the $17^{\text {th }}$ century from the Spanish word "Negro," meaning black. When the actual interpretation and meaning of the "N" word was used intentionally as an insult or racial slur is unclear, but Kennedy (2007), a Harvard professor of law, notes that by the late $18^{\text {th }}$ or early $19^{\text {th }}$ century the term was clearly used as an insult. Today, it is still often used primarily to insult others, but the ethnicity implied may vary from African American to other ethnic groups. Additionally, the "N" word has more recently been used as a sign of affection or term of endearment to those sharing an African American cultural background. An important function, purpose, and scope of the current study was in identifying under what conditions and circumstances this historically offensive term is now being used by in-group (African American) versus out-group (non-African American) members.

Given the tremendously powerful impact that these offensive terms may have on individuals as well as groups of people, my colleagues and I decided to investigate current perceptions regarding how the "N" word is actually used among African Americans as well as members of other ethnic backgrounds. Additionally, we explored three different academic levels of higher education: the community college level (which serves predominantly underrepresented students), the state university level (which is ethnically diverse with various economic levels of students), and finally a graduate level (Pepperdine University), which serves primarily affluent students.

\section{Why is the "N" Word Used Today?}

Given the fact that the use of the "N" word has evolved into two very distinct and powerful yet also very diametrically opposed groups (those who strongly support its use within racial context and those who become 
offended by its use, regardless of how it is used or who uses it), we decided that this was an important topic of cultural psychology to pursue and investigate.

The purpose of this correlational study is to explore and to analyze the relationship between the responses of ethnic minority students who were involved in a community service project that serves ethnically diverse community college students and their perceptions in the justification regarding the use of the " $\mathrm{N}$ " word. We compared these responses with a second group of participants who were not involved in any community service project. We predicted that an inverse correlation would emerge where experiences in working within an ethnically diverse community service project would sensitize participants to the original meaning of the " $\mathrm{N}$ " word and thus prevent them from using the "N" word today in a more colloquial and "mainstream" style. Thus, the more each student participated in a community service (gardening) program, we predicted the less likely they would be in reporting the justification of the use of the " $\mathrm{N}$ " word.

A second purpose of the study explored the relationship between students who were enrolled in higher education and their perceptions of the legitimacy or justification in the use of the " $\mathrm{N}$ " word. We predicted that a second inverse correlation would emerge where the perceptions of the legitimacy or justification in the use of the "N" word would decrease as educational levels increased.

An important scope of the study was in determining how participants felt about community service involvement and volunteer work with other ethnically diverse group members. In this brief correlational study students were asked several questions pertaining to their feelings about how the word is actually used and under what context it may or may not be used appropriately (see appendix). We were also interested in determining if any type of correlation existed among those students who participated in community service work and their attitudes in the justification of using the "N" word. Students were interviewed and asked ten basic questions pertaining to the use of the "N" word as well as their opinions about what the word actually represented today. The results and ramifications of the study as well as suggestions for future research are offered below.

\section{Method}

\section{Participants}

Participants $(\mathrm{N}=181)$ were randomly selected from four higher educational institutions serving distinct populations of students (two-year community colleges, public four-year state university, and private graduate school). Fifty-six (26 males; 30 females) of the participants were enrolled at Compton Community College (a community college located in South Central Los Angeles serving predominantly low-income and underrepresented students). Seventyfive percent (42) of the participants from Compton Community College self-identified as "African American" and the remaining participants (14) were self-identified as "Hispanic." Forty-five participants ( 30 females and 15 males) were from a second community college (Pierce College) that is located in an affluent upper-income suburb of the San Fernando Valley, California. Thirty-one (68\%) of the participants self-identified as "Caucasian" and the remainder (32\%) self-identified as "Hispanic." Seventy-two participants (48 females and 24 males) were from California State University Northridge (CSUN) undergraduate psychology course (a state university that represents an ethnically diverse student body located in the San Fernando Valley, primarily serving middle-income students). Forty-three (60\%) of the participants from CSUN self-identified as "Caucasian," 20 (27\%) self-identified as "Hispanic," and nine (13\%) remaining participants self-identified as "African American." The final selection of participants included eight graduate students (100\% self-identified as "Caucasian") who were randomly selected from Pepperdine University (a private religious university that primarily serves economically affluent students).

\section{Measures}

All participants were administered the "The Use of the ' $N$ ' Word: Is It Ever Okay to Use?" questionnaire (see Appendix A). This questionnaire is a ten-item Likert-based self-report questionnaire that asked questions relative to perceptions of the appropriateness in using the " $\mathrm{N}$ " word in a variety of different social and peer-related situations (i.e., "I feel that only if you are a person of minority descent, then it is okay to use with your friends," or, "I think that if more people were aware of what the "N" word really represents, younger people would be less likely to use it."). The reliability of the questions measuring attitudes relevant to the use of the "N" word was high $(r=.90)$.

Similarly, the "Attitudes of Community Service Work" (ACSW) questionnaire was based on a ten-question Likert-based self-report questionnaire that asked questions pertaining to the perceptions of the value of community service work among members from different ethnic groups (i.e., "I feel that it is important for different ethnic groups to work together on community projects," or, "I believe that community service programs (such as gardening) can 
help students to identify their vocational strengths and career interests."). The reliability of the ACSW measure was also strong, with a coefficient alpha of .80 .

\section{Procedure}

All participants $(\mathrm{N}=181)$ were administered the questionnaire during the course of their enrollment in psychology courses during the Fall 2007 and Spring 2008 terms. The participants who were involved in the community service project were administered the "The Use of the 'N' Word: Is It Ever Okay to Use?" questionnaire after completing their community service work and the scores (with anecdotal comments) were recorded.

\section{Community Service Work via Gardening Activities on Campus}

The community service gardening program at Compton Community College is a volunteer program where students collaboratively work toward a common goal of improving the physical appearance of the Compton campus. The purpose of the gardening program was to create and maintain a community garden consisting of fruit trees, vegetables, and flowers over a two-acre parcel of land on the campus. The groups of students participating in the program are ethnically diverse and their experiences in cooperative group work and community service activities are intended to provide insight to the cultures and backgrounds of all students participating in the program. Participants were randomly assigned to a variety of gardening-related tasks (i.e., cultivating and amending soil, planting citrus or stone-fruit trees, flowers and vegetables). Students rotated their partners on a weekly basis so that all participants had opportunities to work with each person involved in the community gardening program.

The students who volunteered in the program worked over a period of one semester (16 weeks) averaging 10 to 15 hours per semester. Compton students were paired with fellow students and one individual mentor from CSUN, who provided instructions and assistance in planting the plants, fruit trees, and vegetables in the campus garden. A key element that was central to the study was the interethnic interaction while participants completed their gardening assignments. While completing the community gardening program, all of the participants were encouraged to collaborate and communicate with their partners as a means of better understanding each other's culture, identity, and ethnic backgrounds.

This interethnic activity provided students with an opportunity to work with each other and to better understand the diverse cultures that were associated with all of the students from different backgrounds. More importantly, the interaction among the students provided a unique environment where they could discuss their backgrounds, future plans in education, and to develop a strong friendship and bond with the other students. At the end of the semester the students typically shared the fruits and vegetables that were grown in the garden. Each participant was also instructed to write a short essay on his or her experiences during the community service gardening program.

The Compton Community College participants lived typically within the five- to 10 -square-mile area in a blighted urban portion of southeast Los Angeles. For many of the participants from the Compton district, their sole means of transportation was a public bus system, which typically required 45 to 90 minutes travel time. The participants in the Compton Community College sample were typically single parents on a fixed income, with over $80 \%$ receiving some form of financial aid to complete their education.

The average mean income of the Compton College participants $(n=56)$ ranged from $\$ 20,000-\$ 33,000$ annually. The participants in the California State University Northridge sample $(n=72)$ had a mean income of $\$ 45,000$ - \$70,000, with many participants still living at home with their parents and experiencing financial support that was typically not available for the Compton students. The participants from Pierce college $(n=45)$ typically represented middle-income status (average income \$45,000 - \$75,000) and was comprised primarily of first-year college students residing at home with their parents. Finally, the participants in the third group, Pepperdine University $(n=8)$, ranked highest in income (average income over $\$ 90,000$ annually) and consisted primarily of Caucasian graduate students of psychology.

\section{Results}

An ANOVA was conducted to compare responses of the community college students with responses from the fouryear state university students and the graduate level students. While no overall significant interaction was observed between community service activities, levels of education, and scores from the UNW test, some significant differences were observed in response to specific questions posed from the "The Use of the ' $N$ ' Word: Is It Ever 
Okay to Use?" questionnaire (see table 1). Specifically, question 2, "I think that it is inappropriate for any ethnic group to use the 'N' word," and question 8, "I feel that how the "N Word" is used today is very different than what it represented in the days of slavery," showed the strongest interaction, where $t(83)=-4.19, \mathrm{p}<.0001$ and $t(83)=$ $4.49, \mathrm{p}<.0001$ respectively (see tables 1 and 3). No overall significant relationship emerged between CSW activities and perceptions in the justification of the "N word" where $t(83)=-1.88, \mathrm{p}>.06$ (see table 2). Finally, no significant relationship existed relative to gender and perceptions in the justification of the use of the "N word." However, females scored slightly higher $(35.32 ; \mathrm{SD}=4.84)$ than males $(32.20 ; \mathrm{SD}=5.80)$ in rejecting the use of the "N word" (see table 4).

\section{Discussion}

The purpose of this correlational study was to explore the relationship between education, community service work, and perceptions of the justification of the use of the "N" word. Regardless how the word is actually used, there are few topics or phrases used today that can elicit more emotional reaction and controversy than the "N" word. While literally every ethnic group has several derogatory terms or slurs used in their reference, we submit that the " $\mathrm{N}$ " word is unique in its ability to offend so many people, yet paradoxically may be used often as a sign of endearment or affection among in-group and out-group members. During the course of the study students responded to the questionnaire very strongly and attempted to justify their reasoning in a number of ways.

Table 1 
Journal of Praxis in Multicultural Education, Vol. 4, No. 1 [2010], Art. 3

Table 2

Table 3

\begin{tabular}{|c|c|c|c|c|c|c|c|c|c|c|c|c|}
\hline \multicolumn{2}{|l|}{ School } & UNW & UNW & UNW & UNW & UNW & UNW & UNW & UNW & UNW & UNW & UNW Total \\
\hline \multirow{3}{*}{ Compton } & Mean & 3.3 & 3.5 & 3.9 & 2.2 & 4.5 & 3.2 & 2.3 & 3.7 & 3.5 & 4.1 & 34.5 \\
\hline & $\mathrm{N}$ & 5 & 5 & 5 & 5 & 5 & 5 & 5 & 5 & 5 & 5 & 5 \\
\hline & Std. & 1.35 & 1.41 & 1.11 & 1.34 & 0.88 & 1.35 & 1.41 & 1.07 & 1.36 & 1.12 & 5.18 \\
\hline \multirow{3}{*}{ SUN } & Mean & 3.1 & 3.5 & 3.6 & 2.5 & 4.3 & 3 & 2.7 & 3.7 & 3.5 & 4.5 & 34.6 \\
\hline & $\mathrm{N}$ & 2 & 2 & 2 & 2 & 2 & 2 & 2 & 2 & 2 & 2 & 2 \\
\hline & Std. & 1.37 & 1.57 & 1.61 & 1.52 & 1.2 & 1.54 & 1.43 & 1.39 & 1.31 & 0.69 & 6.91 \\
\hline \multirow{3}{*}{ Pepper-dine } & Mean & 4.5 & 4.1 & 4.2 & 2.7 & 4.3 & 3 & 3.8 & 3.5 & 4.6 & 4 & 39 \\
\hline & $\mathrm{N}$ & 8 & 8 & 8 & 8 & 8 & 8 & 8 & 8 & 8 & 8 & 8 \\
\hline & Std. & 0.53 & 0.64 & 0.46 & 1.16 & 1.4 & 1.3 & 1.24 & 1.41 & 0.51 & 1.19 & \\
\hline Peirce & Mean & 3.5 & 3.6 & 3.6 & 2.3 & 4.2 & 3 & 2.8 & 3.8 & 3.7 & 4 & 35 \\
\hline
\end{tabular}


Hoffman et al.: Changing perceptions in the justification of the use of the " $\mathrm{N}$ " $\mathrm{W}$

\begin{tabular}{|c|c|c|c|c|c|c|c|c|c|c|c|c|}
\hline & $\mathrm{N}$ & 4 & 4 & 4 & 4 & 4 & 4 & 4 & 4 & 4 & 4 & 4 \\
\hline & Std. & 1.19 & 1.26 & 1.24 & 1.1 & 1 & 1.41 & 1.36 & 1.07 & 1.1 & 1.13 & 6.03 \\
\hline \multirow{3}{*}{ Total } & Mean & 3.3 & 3.5 & 3.7 & 2.4 & 4.3 & 3.1 & 2.6 & 3.8 & 3.6 & 4.1 & 34.8 \\
\hline & $\mathrm{N}$ & 18 & 18 & 18 & 18 & 17 & 18 & 17 & 18 & 18 & 18 & 18 \\
\hline & Std. & 1.3 & 1.36 & 1.26 & 1.3 & 1.02 & 1.38 & 1.41 & 1.12 & 1.28 & 1.06 & 5.54 \\
\hline
\end{tabular}

Table 4

QuickTime $^{\mathrm{TM}}$ and a are needed to see this picture.

Responses to many of the questions were split where people felt very passionate about their position relative to this topic and felt compelled to justify their position. Rarely did individuals (regardless of their ethnicity) indicate that they had little to say when asked about their belief in the appropriateness of using the "N" word. While no overall significant differences were observed in the justification of the "N" word among participants who were 
involved in community service activities and levels of education, some interesting and significant trends did emerge relative to specific questions posed by the UNW questionnaire.

For example, questions 1, "When I hear the ' $\mathrm{N}$ ' word it bothers me," and 8, "I feel how the ' $\mathrm{N}$ ' word is used today is very different than what it represented in the days of slavery," did show significant effects relative to education. For example, the Compton (community college) mean response to question 2 was 3.59 (SD = 1.41), whereas the Pepperdine University (graduate level) response was higher, indicating a stronger belief in the inappropriateness in using the " $\mathrm{N}$ " word under any circumstances $(4.13 ; \mathrm{SD}=.641$; see table 3$)$.

Students who supported the use of the "N" word indicated that the term itself has significantly changed meaning and has become mollified through everyday use by various ethnic groups. These students further justified their use of the "N" word by saying that the term today, "simply is another word indicating or referring to friendship...when I say hello to my friends I may as well be saying something like, 'What's up my nigga?"' Other students who supported the use of the " $\mathrm{N}$ " word also indicated that the actual term had changed into more of a colloquial dialect, meaning "nigga" now takes on an entirely different context and interpretation than the literal term "Nigger." Thus, how the term is pronounced may carry either positive or pejorative interpretations.

The bifurcating nature of the term itself has created animosity among ethnically diverse groups and thus served as the impetus of our research. We have discovered that this term elicits powerful reactions from just about every ethnic group and economic class of individuals residing within our community today. We were able to identify several important psychological themes that relate to interethnic attitudes and communication that determined whether or not individuals felt that the use of the term " $N$ " word was justifiable or not.

We hypothesized that one reason why involvement and participation in community service work may yield a greater sensitivity toward and reluctance to use of the "N" word was due to the exposure that the students had to each other and a development of pride and respect for other students, regardless of their ethnic background. While the results of the study did not support this hypothesis, anecdotal interviews with the participants indicated that many of the students "enjoyed working with other students from different backgrounds [and] felt that they were better able to understand persons from different ethnic backgrounds." One participant indicated, "Getting to know people through community service work allowed me to better understand and respect persons from different backgrounds."

In a sense, then, the community service work sensitized students from different socioeconomic and ethnic backgrounds and helped them to discover personal similarities between one another. Their strong friendships and bonds that emerged from the community service work helped to create strong ties between one another and to reduce negative ethnic stereotypes that may have emerged without the community service work experiences. Differing perceptions of the justification of the use of the "N" word exist among students who are actively involved in community service projects compared to those students who are not actively involved in a community service program. Perhaps more involvement with interethnic community service work activities may help individuals from all ethnic backgrounds to realize the potentially damaging impact these words carry, regardless of their intended use.

Some of the participants who were actively involved in the community service projects indicated that they felt the use of the "N" word was essentially unjustified, regardless in what type of context it was used. We suggest the interethnic community service that the participants engaged in helped them to feel more cohesive and unified and less likely to characterize each other by race. One participant, Kevin, informed the researchers that, "After working together in this group over several weeks, I don't feel that I can characterize them any longer by color or class - they are just my friends working together to improve the college."

Another Compton Community College student, Mannie, who had participated in the community service gardening program indicated that his experiences in working with other students helped him to become more sensitized to the problems of discrimination and certain words seemed to exacerbate race relations:

\footnotetext{
"African-Americans around my age sling the "N" word around as part of regular conversation and lyrics of rap are littered with it. Many of the older folks look down on the word with the feeling that they fought during the civil rights movement to erase it from the nation's vocabulary...but it is still used today as if the movement never existed! So, by me writing this reflection and my work with the other students in helping to improve the college [community gardening work]...I will improve myself and my community by not using the word 'Nigga [sic].' Instead, I will use the word 'brother' because like I said...we are all really just brothers."
}

Age was another interesting factor that surfaced in the current study. Generally speaking, younger respondents (i.e., under 30) were more likely to perceive the "N" word as essentially innocuous or neutral in daily use, whereas older respondents (i.e., ages 30 and older) were more likely to cite the "inappropriateness and offensiveness" and "ethnically deteriorating effect" that the term could have on all individuals. More importantly, 
however, was the fact that older African American participants were more likely to associate the "N" word with its original meaning and history, dating back to the days of slavery and injustices based on ethnicity and heritage.

One middle-aged African American stated, "It doesn't yet bother them [the younger students] because they do not yet fully understand how racism can affect people and their lives. Only over time, when you mature and gain wisdom through your experiences and you have been turned down for jobs or pulled over [by the police] do you realize that the "N" word is not some friendly term you call your friends. The term itself represents something actually very hateful and tears people and families apart. It just comes with age, I guess."

One final factor to consider in the study was that of gender. While the study did not show significant differences in gender and perceptions in the justifications of the " $\mathrm{N}$ " word, results showed that, overall, female participants tended to agree that the use of the "N" word was more offensive and inappropriate than male participants (female mean UNW total score $=35.32 ; \mathrm{SD}=4.84$; male mean $\mathrm{UNW}$ total score $=32.20 ; \mathrm{SD}=5.80$; see table 4).

Students who were involved in the community service projects indicated that the "N" word to them represented a vulgar and offensive racial slur and that it could not be transformed into a colloquial term even among long-term friends who may have been of African American descent. By a significant margin (over 75\%) of the African American students with little or no community service experiences had indicated that the use of the word did not offend them whatsoever. Additionally, the vast majority of the students indicated that they felt "justified" in using the term because of a sense of "ownership" of the word itself. Several of the students who were interviewed indicated that because the use of the "N" word was primarily used among African Americans, it represented one method for them to remain cohesive and unified with each other.

Experiences from interethnic community service work allowed for effective interaction and friendships without regard to ethnicity or class. Those students not participating in the community service project remained more ethnically homogeneous in their interactions with other students and thus perhaps felt more compelled to use the "N" word as sign of bonding and identification with each other.

As a final note, we suggest that as a community, we re-evaluate why the " $\mathrm{N}$ " word has become so controversial to so many people. We submit (and hope) that if individuals today are sensitized and educated to the horrific nature and intended dehumanizing aspect of the " $\mathrm{N}$ " word, then its current popularity and appeal to younger generations will decrease significantly. Perhaps, with the development of more community service projects that embrace individuals from varied ethnic backgrounds, there will be less inclination to use terms that have been historically designed to denigrate, humiliate, and encourage hate.

\section{References}

Blair, L. V. (2001). Implicit stereotypes and prejudice. In G. B. Moscowitz (Ed.), Cognitive social psychology. Mahwah, NJ: Erlbaum.

Bobo, L. (1983). Whites' opposition to busing: Symbolic racism or realistic group conflict? Journal of Personality and Social Psychology, 45, 1196-1210.

Bobo, L. (2000). Race and beliefs about affirmative action. In D. O. Sears, J. Sidanious, and L. Bobo (Eds.), Racialized politics: The debate about racism in America (pp.137-164). Chicago: University of Chicago Press.

Bond, M. H. (1983). How language variation affects inter-cultural differentiation of values by Hong Kong bilinguals. Journal of Language and Social Psychology, 2, 57-66.

Branscombe, N. R., \& Wann, D. L. (1994). Collective self-esteem consequences of outgroup derogation when a valued social identity is on trial. European Journal of Social Psychology, 24, 641-657

Brewer, M. B. \& Kramer, R (1984). The psychology of intergroup attitudes and behavior. Annual Review of Psychology, 36, 219-243.

Brody, N. (2007). Barriers to understanding racial differences in intelligence. Perspectives on Psychological Science, 2, 214-220.

DeSteno, D., Dasgupta, N., Bartlett, M., \& Cajdric, A. (2004). Prejudice from thin air: The effect of emotion on automatic intergroup attitudes. Psychological Science, 15(5), 319-323.

Ferber, J. (2007). Encouraging a culture of interest in others: American and Russian children connect. Community Works Journal, 13-16.

Hoffman, A.J., \& Wallach. J.N. (2006). Improving interpersonal communication through community service work and a campus gardening project: Leave the cell phones at home. The Community College Enterprise. 
Kennedy, R. (2007). A Note on the "N" Word. Towards Racial Equality: Harpers Weekly Reports on Black America (1857-1874).

Lakoff, R. (2000). The language of war. University of California Press.

Levine, S., van Laar, C., \& Sidanious, J. (2003). The effects of ingroup and outgroup friendship on ethnic attitudes in college: A longitudinal study. Group Processes and Intergroup Relations, 6 , 76-92.

Low, B. E. (200). Hip-hop, language, and difference: The N-Word as a pedagogical limit-case. Journal of Language, Identity, and Education, 6(2), 147-160.

Matsumoto, D. \& Seung, H. Y. (2007). Toward a new generation of cross-cultural research. Perspectives on Psychological Science, 3, 251-269.

Motley, C. M. \& Craig-Henderson, K. M. (2007). Epithet or endearment? An examination of cultural contexts and reactions. Journal of Black Studies, 37(6), 944-963.

Saucier, D. A., Hockett, J. M., \& Wallenberg, A. S. (2008). The impact of racial slurs and racism on the perceptions and punishment of violent crime. Journal of Interpersonal Violence, 23(5), 685-701.

Stokoe, E. (2007). Black this, Black that: Racial insults and reported speech in neighbor complaints and police interrogations. Discourse \& Society, 18(3), 337-372.

Vorauer, J. D. \& Sakamoto, Y. (2006). I thought we could be friends, but .... Systematic miscommunication and defensive distancing as obstacles to cross-group friendship formation. Psychological Science, 17(4), 326331.

White, R. K. (1977). Misperception in the Arab-Israeli conflict. Journal of Social Issues, 33, 190-221. 


\section{Appendix A}

"The Use of the "N" Word:

Is It Ever Okay to Use?"

Please answer each question with a score of " 1 " through " 5 ," where scores indicate:

$1=$ Strongly disagree;

$2=$ Disagree somewhat;

$3=$ Not sure / Don't know;

$4=$ Agree somewhat;

$5=$ Strongly agree

1. When I hear people using the " $\mathrm{N}$ " word - it bothers me ;

2. I think that it is inappropriate for any ethnic group to use the " $N$ " word

3. I think that if more people were aware of what the "N" word truly represents, younger people would be less likely to use it

4. I feel that only if you are a person of minority descent (i.e., African American), is it okay to use with your friends

5. I feel that parents of all ethnic backgrounds should teach their children that the use of some words (i.e., the "N" word) is inappropriate and should not be used

6. I think most people are aware what the " $\mathrm{N}$ " word really represents

7. I feel that when people use the "N" word, it keeps people aware of the problems relative to past slavery, prejudice, and discrimination that has occurred in the United States

8. I feel that how the " $\mathrm{N}$ " word is used today is very different than what it represented in the days of slavery

9. I feel that when people use the "N" word it really is a form of disrespect to African Americans

10. I feel that both prejudice and discrimination are problems that can be resolved if all people continue to work together 


\section{Appendix B}

Attitudes of Community Service Work

Please answer each question with a score of "1" through "5", where scores indicate:

$1=$ Strongly disagree;

$2=$ Disagree somewhat;

$3=$ Not sure / Don't know;

4 = Agree somewhat;

$5=$ Strongly agree

\section{Community Service Attitude Scale}

1. I feel that it is important for different ethnic groups to work together on community projects

2. I feel that it is possible for people from different cultural and ethnic backgrounds to live and work together in harmony

3. I believe when people from all backgrounds work together on a common project, people tend to understand each other better and get along more

4. I believe that ethnic diversity can strengthen and improve our community in many different ways

5. I am just as likely to establish friendships and communicate with members of different ethnic groups as my own ethnic group

6. I believe that racism and discrimination are traits that are learned (not something that is inherited) and if something is learned, it may be "unlearned"

7. I believe that our school systems (such as high schools and primary schools) should develop community service projects for the students to get involved with (i.e., help clean litter, plant gardens, work in food shelters, etc.)

8. Higher educational systems and communities both work more effectively for students when they establish programs that encourage ethnically diverse groups to work together

9. I believe community service programs can help children to become more autonomous and responsible persons as adults

10. I believe that community service programs (such as gardening) can help students to identify their vocational strengths and career interests 